\title{
A Formação da Força de Trabalho Maritima no Brasil: Cultura e Cotidiano, Tradição e Resistência (1808-1850)*
}

José Carlos Barreiro ${ }^{\text {ख内 }}$

O Brasil se apresentou, desde o século XVI, como uma das peças centrais do nascimento de uma ordem econômica e social, em que o navio se configurava como um espaço de lutas e contradições entre governantes, comandantes e marinheiros. Estudaremos aqui o processo de proletarização que transformou índios, pequenos roceiros, negros livres e escravos em força de trabalho marítima no Brasil do início até meados do século XIX.

Palavras-chave: trabalho marítimo; cultura marítima; Brasil e sistema Atlântico.

Formation Of The Maritime Labor Force In Brazil: Culture And Daily Life, Tradition And Resistance (1808-1850).

Since the $16^{\text {th }}$ Century, Brazil has played a major role in the rise of a new economical and social order, in which ships represented a space of struggle and contradictions among rulers, captains and sailors. This article will study the proletarization process that transformed Indians, small farmers, free and slave black people in maritime labor force in Brazil during the first half of $19^{\text {th }}$ century.

Keywords: maritime labor; maritime culture; Brazil and the Atlantic system.

\footnotetext{
${ }^{\otimes}$ Artigo recebido em março de 2008 e aprovado para publicação em setembro de 2008.

兩 Doutor em História Social pela Universidade de São Paulo. Pós Doutor pela Georgia State University, Atlanta, EUA. Professor Titular de História do Brasil do Departamento de História da Unesp, Campus de Assis. E-mail: jcbarr@assis.unesp.br
} 
La Formation De La Main D’oeuvre Maritime Au Brésil: Culture Et Quotidien, Tradition Et Résistance (1808-1850).

A partir du XVIe siècle, le Brésil surgit comme l'un des éléments centraux du surgissement d'un ordre économique et social dans lequel le navire apparaît comme un espace de luttes et de contradictions entre gouvernements, commandants et marins. Nous examinerons ici le processus de prolétarisation, au Brésil au cours de la premier moitié du XIXe siècle, qui a transformé en main d'œuvre de travail maritime des indiens, des petits agriculteurs, des noirs libres et des esclaves.

Motsclés: travail maritime; culture maritime; Brésil et système Atlantique.

No desenvolvimento da sociedade moderna os oceanos cumpriram um papel histórico extremamente significativo do ponto de vista da interação entre economias e sociedades de todo o mundo. Isto não é menos verdadeiro quando estudamos o Brasil neste contexto. Uma das características históricas mais significativas da sociedade brasileira no período da colonização foi a de ter se constituído como economia costeira e exportadora de produtos primários. A interligação precária das províncias com o interior, a concentração de quase toda a atividade produtiva na faixa litorânea e a própria extensão continental da costa marítima brasileira fez com que o mar tivesse uma importância óbvia na formação histórica da sociedade brasileira. ${ }^{1}$ Neste sentido, a história do Brasil, com seus 7.480 quilômetros de costa e extensos recursos fluviais, é um convite permanente para a historicização dos significados do oceano, lido frequentemente como espaço vazio. ${ }^{2}$ A busca dessa ressignificação pode se tornar ainda mais fascinante se a análise se voltar para o conhecimento do marinheiro como um tipo singular de trabalhador que viveu conflitos ainda pouco conhecidos nas relações sociais, culturais e de trabalho travadas em portos e navios do Brasil e de todo o mundo.

Os portos, o aperfeiçoamento dos navios e a formação do trabalho marítimo se expandiram grandemente desde o início da era moderna, unifi-

\footnotetext{
${ }_{1}^{1}$ Tal precariedade de comunicação ocorria também entre as capitanias, embora algumas exceções significativas devam ser assinaladas. Os exemplos de São Paulo e da área do Sertão do São Francisco vem logo à mente, pois embora as ligações também fossem difíceis, ainda assim conseguiram manter conecções privilegiadas com o interior.

${ }^{2}$ Caio Prado Júnior, Formação do Brasil Contemporâneo: Colônia, $9^{a}$. ed., São Paulo, Brasiliense, 1969, p. 19-32; Alain Corbin, O território do vazio. A praia e o imaginário ocidental, trad. Paulo Neves, São Paulo, Companhia das Letras, 1989; Felix Driver, "Sea-Changes: Historicizing the Ocean, c. 1500 - c. 1900”, History Workshop Journal, 51, Oxford, UK, 2001, p. 278-279.
} 
cando distantes partes do globo, diferentes mercados e modos de produção, congregando economias locais, regionais, nacionais e internacionais. Todos os tipos de produtores acabaram sendo conectados por tais rotas, incluindo caçadores, fazendeiros, sitiantes, mercadores, escravos, artesãos e trabalhadores assalariados em geral. ${ }^{3}$ Tais fundamentos configuraram-se, enfim, como a base das estruturas materiais da economia mundial neste período, cujo caráter global envolveu a descoberta de rotas marítimas interligando o Continente Europeu com as Américas, a África e as Índias, e a criação de espaços de luta como o navio, as terras comunais, a plantation e a fábrica.

O Brasil figurou desde o século XVI como uma das peças centrais do nascimento dessa nova ordem econômica e social, e do surgimento do chamado sistema Atlântico, compondo esse cenário de terror, que envolveu desapropriação e aldeamento de índios, escravização de negros africanos, incorporação de mulatos, mestiços e brancos à sua economia de exportação. A necessidade de trabalhadores marítimos se intensifica desde então, crescendo a demanda por marinheiros para a navegação de cabotagem e para o comércio de escravos, este último em grande parte dominado por traficantes portugueses e brasileiros. Para os fretes marítimos, basicamente feitos por navios estrangeiros, sobretudo ingleses, muitos marinheiros também eram contratados em portos brasileiros. De outro lado, não era menor a demanda por trabalhadores marítimos por parte da Marinha militar, que se constituía em prioridade estratégica na consecução de objetivos voltados para a construção do Estado-Nação no Brasil. Tais objetivos já se anunciavam desde os primeiros movimentos emancipacionistas de fins do século XVIII.

Em minha pesquisa anterior sobre o tema em questão pude reconstituir aspectos importantes a respeito das difíceis condições de constituição da mão de obra marítima, em virtude do caráter rebelde, da inaptidão e da pouca afeição às tarefas que aos marinheiros eram impostas. Muitas de suas crenças alimentavam o antagonismo básico que sustentava o confronto de classe, articulado de um lado ao poder e autoridade do capitão, e, de outro, ao comportamento do marinheiro comum, inserido nas relações de trabalho.

\footnotetext{
${ }^{3}$ A emergência das sociedades modernas (séculos XVI ao XVIII) estudadas em suas dimensões atlânticas, com ênfase no papel dos marinheiros, escravos e trabalhadores assalariados, tem sido tematizada por importantes trabalhos recentes, dentre os quais cabe destacar: Marcus Rediker, Between the Devil and the Deep Blue Sea. Merchant seamen, pirates, and the anglo-american maritime world, 1700-1750, Cambridge, Cambridge University Press, 1987; Peter Linebaugh e Marcus Rediker, The Many Headed Hydra. Sailors, slaves, commoners, and the hidden history of the revolutionary Atlantic, Boston, Beacon Press, 2000.
} 
Estes aspectos foram examinados através da leitura de diários de bordo, memórias de mercadores e narrativas das travessias marítimas feitas por viajantes que vinham de várias partes do mundo em visita ao Brasil. ${ }^{4}$ Parece evidente que a uma sociedade com tais características históricas seja incontestável a influência do mar, da navegação e dos trabalhadores marítimos, compondo seu universo de conflitos e sociabilidades no plano das relações econômicas, sociais e culturais. Contudo, surpreendentemente, a historiografia brasileira era até recentemente bastante lacônica em relação à vida social, econômica e política vinculada às atividades portuárias. Afora os trabalhos mais densos de Amaral Lapa e Kátia Mattoso sobre a construção de navios e as remodelações efetuadas no porto de Salvador nos séculos XVIII e XIX, as referências eram incrivelmente escassas. Cabe ainda registrar a existência isolada de um pequeno artigo de Luiz Mott procurando demonstrar a existência de um sistema de comunicação internacional entre marinheiros, exemplificando com o caso do Haiti, de onde vinham notícias sobre os levantes daquela Colônia, divulgadas entre os escravos do Brasil. ${ }^{5}$

Do ponto de vista da bibliografia internacional os trabalhos mais importantes eram os de Alain Cabantou, Alain Corbin e Jacques Le Goff como suportes teóricos importantes para abordagem da problemática sob o ponto de vista da História das Mentalidades. Os artigos de Bromley e Linebaugh surgidos entre os anos 1980 e 1990 eram e continuam sendo exemplares no que respeita à importância dos marinheiros e sua peculiar participação nos movimentos sociais. ${ }^{6}$

Felizmente este quadro tem mudado, principalmente a partir dos anos 1990, com o surgimento de artigos e teses acadêmicos, muitos dos quais já

\footnotetext{
${ }^{4}$ Relatório de Pesquisa apresentado ao CNPq sob o título O processo de trabalho nos portos e navios e a herança espiritual oceânica. Brasil, 1780-1850. Bolsa de Pesquisa, 1995, 143p.

${ }^{5}$ José Roberto do Amaral Lapa, A Bahia e a Carreira da Índia, São Paulo, Nacional, 1968; Idem, Economia Colonial, São Paulo, Perspectiva, 1973; Kátia de Queiroz Mattoso, Bahia: A cidade do Salvador e seu mercado no século XIX, São Paulo, Hucitec; Salvador, Secr. Municipal de Educação e Cultura, 1978; Luiz B. Mott, "A Revolução dos negros do Haiti e do Brasil”, História: Questões e Debates, Vol. 4, 1982, Uberlândia, p. 55-63.

${ }^{6}$ Alain Cabantous, Le ciel dans la mer. Christianisme et civilization maritime, XVI-XIX siècle, Paris, Fayard, 1990; Alain Corbin, O território do vazio. A praia e o imaginário ocidental, São Paulo, Companhia das Letras, 1989; Jacques Le Goff, "O ocidente medieval e o Oceano Índico: um horizonte onírico". In: Para um novo conceito de Idade Media. Tempo, trabalho e cultura no ocidente, Lisboa, Estampa, 1980; J. S. Bromley, "Bandidos do Mar, 1660-1720: Liberdade, Igualdade e Fraternidade entre os flibusteiros do Caribe”. In: Frederick Krantz (org.), A outra história: ideologia e protesto popular nos séculos XVII a XIX, Rio de Janeiro, Zahar, 1990; Peter Linebaugh, "Crime e Industrialização: a Inglaterra do século XVIII". In: Paulo Sérgio Pinheiro (org.), Crime, violência e poder, São Paulo, Brasiliense, 1983.
} 
publicados, abordando aspectos variados da atividade marítima brasileira em seu conjunto, embora seja ainda surpreendentemente pequena a produção historiográfica devotada à reflexão sobre o mar e os marinheiros no Brasil, desde a época em que José Honório Rodrigues fez referência a essa escassez em fins dos anos cinquenta do século XX, em seu livro sobre historiografia e historiadores brasileiros. ${ }^{7}$ Avanços significativos no plano teórico têm vindo à tona também através de pesquisas de autores devotados ao estudo da emergência das sociedades modernas (séculos XVI ao XVIII) estudadas em suas dimensões atlânticas, com ênfase no papel dos marinheiros, escravos e trabalhadores assalariados, temas estes estudados pelos trabalhos recentes de Rediker e Linebaugh. ${ }^{8}$

No Brasil havia população potencialmente disponível para o trabalho marítimo, mas que podia, por diversos meios, subsistir com facilidade, apropriando-se de recursos da natureza para a sua própria sobrevivência. Foi necessário então o desenvolvimento de um processo brutal de recrutamentos forçados que desagregou famílias de pequenos roceiros e comunidades indígenas de todo o Brasil. Em trabalho cooperativo entre o Chefe de Polícia da Corte, o Ministro da Marinha e os Presidentes de Província, ordens de prisões e recapturas de marinheiros fugidos eram expedidas às centenas, atingindo crianças e adolescentes, escravos de ganho, chefes de família e até mesmo estrangeiros que perambulavam pelas imediações dos portos.

Contudo, esse processo amplo de proletarização, através do qual homens eram arrancados da terra, teve que vir acompanhado da organização e disciplinarização dessa "força de trabalho", sem as quais os lucros dos capitães

\footnotetext{
${ }^{7}$ Cf. José Honónio Rodrigues, "O Sentido da História Naval”. In: História e Historiadores do Brasil, São Paulo, Fulgor, s/d., p. 110-116. Contudo, não se pode deixar de enfatizar as significativas contribuições de trabalhos sobre o tema que surgiram desde então. Dentre eles cabe destacar: Marcos Antonio Silva, Contra a Chibata: marinheiros brasileiros em 1910, São Paulo, Brasiliense, 1982; Luiz Geraldo Silva, A Faina, a festa e o rito. Uma etnografia histórica sobre as gentes do mar (séc. XVII ao XIX), São Paulo, Papirus, 2001; Jaime Rodrigues, De Costa a Costa. Escravos, marinheiros e intermediários do tráfico negreiro de Angola ao Rio de Janeiro (1780-1860), São Paulo, Companhia das Letras, 2005; Paulo Miceli, O ponto onde estamos: viagens e viajantes na história da expansão e da conquista, São Paulo, Scritta, 1994; Luiz Felipe de Alencastro, O trato dos viventes. Formação do Brasil no Atlântico Sul (Séculos XVI e XVII), São Paulo, Companhia das Letras, 2000; J. M. Arias Neto, "Marinha do Brasil como imagem da nação: o pensamento de monarquistas e republicanos sobre a Marinha do Brasil em fins do século XIX”, Revista Marítima Brasileira, Vol. 121, n. 7/9, Rio de Janeiro, 2001, p. 105-115. ${ }^{8}$ Marcus Rediker, op. cit.; Peter Linebaugh e Marcus Rediker, op. cit.
} 
de navio e os objetivos da Marinha brasileira ficavam comprometidos. Apenas o marinheiro disciplinarizado poderia vencer as duras condições de trabalho existentes, tanto na Marinha mercante costeira e internacional, quanto na Marinha militar. Se livre, ele teria que se transformar progressivamente em força de trabalho; se escravo, teria que se constituir em mercadoria, que, junto com a força de trabalho livre, pudesse ser calculada numa equação com outras coisas. Na Marinha mercante, posto em relação com o capital, com terras, com mercadores e outras mercadorias, deveria ser aferida a sua eficácia na maximização do lucro dos proprietários e capitães de navios. Na Marinha militar, o marinheiro disciplinado seria vital nas lutas contra os vários movimentos provinciais que retardavam a criação de um Estado unificado e nas Campanhas externas como as que o Brasil travou nas Guerras da Cisplatina e do Paraguai, para reforçar e consolidar uma ideologia nacionalista.

Concebendo o navio como um espaço de lutas e contradições entre governantes, comandantes e marinheiros, pretendemos discorrer aqui sobre o projeto de disciplinarização da força de trabalho desenvolvido pela Marinha brasileira, num momento em que a participação do Brasil na comunidade Atlântica, sobretudo a partir dos primeiros anos do século XIX, ganha uma nova dinâmica. Por volta deste período serão rompidas as travas monopolistas do Antigo Sistema Colonial, sendo permitida a livre circulação e troca de mercadorias promovidas por navios de bandeiras e nações de todo o mundo.

O tema da disciplina dos marinheiros tem sido abordado de forma a obscurecer os aspectos mais dramáticos das relações de trabalho nos navios, portos e arsenais. Isto é particularmente verdadeiro em relação à literatura historiográfica produzida por antigos integrantes da Marinha militar brasileira que ocuparam cargos hierarquicamente elevados nesta instituição. Sob o pretexto de corrigir distorções interpretativas que apresentavam a Marinha de forma desprestigiada e humilhada, velhos comandantes da Marinha brasileira construíram em suas memórias uma visão segundo a qual a vida do marinheiro nos navios seria a recriação da harmonia e fraternidade por ele vivida no seio de sua própria família. Desta espécie de "unida família do mar” derivariam as características psicológicas positivas do feliz e bem humorado marinheiro brasileiro. ${ }^{9}$

\footnotetext{
${ }^{9}$ Exemplar sob este aspecto é o trabalho de P. B. Lynch. Cf. P. B. Lynch, Reminiscências da vida de nossa gente do mar, Rio de Janeiro, Serviço Geral da Documentação da Marinha, 1961, p. 4-11.
} 
Outro mito, este veiculado desde os primórdios da formação da Marinha militar brasileira por Ministros, altos funcionários e oficiais da Marinha, refere-se ao entendimento de que a tripulação de um navio formava uma verdadeira corporação. De fato, em certo sentido assim o era. Os navios militares, tanto quanto os navios mercantes, tinham de sair para mar aberto em missões de treinamento e de guerra. E isto colocava a tripulação do navio diante de uma confrontação básica: a do homem com a natureza. Esta confrontação expunha-os a toda sorte de sacrifícios e lutas para sobreviverem em face das forças imediatas e onipotentes de alto-mar. A sobrevivência de todos exigia que nas horas de perigo o navio se transformasse numa verdadeira coletividade em termos de coragem, tarefas e objetivos. Trata-se de uma concepção que tem uma abrangência internacional e vem pelo menos da época dos descobrimentos. Rediker, deparando com esta questão ao estudar o mundo marítimo anglo-americano na primeira metade do século XVIII, desnudou as tensões que jaziam por detrás dessa "comunidade fraterna", abrindo caminhos para revelarmos os componentes de tensão que alimentavam esse processo. ${ }^{10}$

Contrapondo-se às ideias do marinheiro feliz e da corporação unida para vencer a natureza, pretendemos explorar aqui o aspecto que exerceu influência decisiva no desenvolvimento da cultura marítima: a do conflito entre o homem e o homem, que alimentou permanentes confrontos de classe articulados ao poder, autoridade, trabalho e disciplina. Estes confrontos geravam uma subcultura ou uma cultura de oposição partilhada por marinheiros comuns, assentada em valores, atitudes e práticas específicas. Sob este prisma, a corporação do navio e a cultura marítima apresentavam-se fraturadas. Os marinheiros comuns provinham de etnias, raças e nações as mais diversas. Índios e negros de diversas tribos misturavam-se a mestiços e brancos livres e pobres do Brasil e de outros países, formando uma cultura popular diversificada na base da pirâmide social do navio. No topo dessa pirâmide encontravam-se o capitão e os oficiais de alto e médio escalão. Cabia a eles, pois, neutralizar a força da cultura popular proveniente da base dessa pirâmide, criando comportamentos homogêneos compatíveis com a disciplina requerida do marinheiro. A disciplina e a obediência hierárquica só seriam conseguidas se fosse possível neutralizar ao máximo os conflitos decorrentes dessa confrontação.

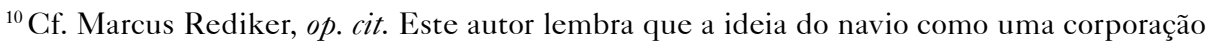
unida para enfrentar a fúria da natureza contra os naufrágios terá provavelmente dado origem ao adágio "estamos todos juntos no mesmo barco".
} 


\section{Uma cultura "rebelde"}

As difíceis condições de constituição da mão de obra marítima determinavam que os marinheiros se revelassem inaptos, rebeldes e pouco afeitos às tarefas que lhes eram impostas. A sua cultura, suas formas diversificadas de sociabilidades e suas condições de vida e trabalho formavam uma totalidade indissociada da vida cotidiana e das relações de classe do navio, o que tornava difícil sua transformação em força de trabalho.

Muitas de suas crenças alimentavam o antagonismo básico que sustentava o confronto de classe, articulado de um lado ao poder e autoridade do capitão, e, de outro, ao comportamento do marinheiro comum, inserido nas relações de trabalho. Os diários de bordo, as memórias de mercadores ou as narrativas das travessias marítimas feitas por viajantes que vinham de várias partes do mundo em visita ao Brasil são registros importantes para a reconstituição dos conflitos e da cultura marítima. Este é o caso das anotações deixadas pelo norte-americano Thomas Ewbank, por ocasião da viagem que fez ao Brasil em meados do século XIX, a bordo do navio Mazzeppa. Durante a travessia ouviu dos marinheiros a lenda das procelárias, segundo a qual esses minúsculos animais eram amantes dos mares tempestuosos e, incansáveis, não conheciam repouso. A superstição dizia ainda que tais aves eram almas infelizes de marinheiros mortos, ao passo que as grandes gaivotas e os enormes albatrozes eram almas dos imediatos e contramestres cruéis. Este relato permite identificar elementos importantes da consciência desses trabalhadores. É possível perceber que eles reconheciam a existência de uma hierarquia no interior do navio, estabelecendo a separação entre trabalhadores e a direção despótica do capital, personificada nos "imediatos" e "contramestres cruéis". Definia-se aí uma situação em que a identificação do opressor permitia o reconhecimento da situação de intensa exploração a que eram submetidos. Os aspectos sobrenaturais presentes na lenda das procelárias, segundo os quais as almas dos marinheiros mortos transformavam-se em aves sobrevoando a popa dos navios, podem estar ligados a uma tradição que remonta à época da expansão ultramarina de fins do século XV, e que explicava o sofrimento da travessia marítima para os marinheiros. Com efeito, no imaginário europeu, desde o início da expansão ultramarina, a travessia marítima e o mundo colonial eram considerados regiões em que as almas padeciam para pagar seus pecados. ${ }^{11}$

${ }^{11}$ Laura de Mello e Souza, O Diabo e a Terra de Santa Crus: feitiçaria e religiosidade popular 
Registros importantes sobre as tensões manifestadas na exteriorização das crenças dos marinheiros podem também ser encontrados em narrativas de travessias marítimas como as do reverendo inglês George Walsh, de 1828. ${ }^{12}$ Walsh assistiu e descreveu o batismo do marinheiro, um clássico rito de passagem, quando fazia a travessia marítima da Inglaterra para o Brasil a bordo do navio Gallatea. O ritual visava batizar os noviços que atravessavam pela primeira vez a linha, isto é, o Equador. Era praticado por marinheiros de todas as nacionalidades, sendo, portanto, parte de uma cultura marítima internacional. Caracterizava-se, antes de tudo, por muito barulho e muita agitação, nos moldes dos rituais populares terrenos da Inglaterra do século XVIII, descritos e estudados por Thompson e por ele denominados de rough music. Guardava também próximo parentesco com os charivaris franceses tão bem estudados por Natalie Davis, ${ }^{13}$ cujas raízes estendiam-se desde a França rural do século XIII.

Assim como no charivari, o popular espetáculo da sociedade terrena, a disciplina do navio era momentaneamente relaxada, restando poucas barreiras entre o capitão e a tripulação em festa. Alguns capitães distanciavam-se das festividades provavelmente com o intuito de manter a autoridade sobre os marinheiros. Outros dela evitavam participar por acharem o ritual muito "pagão". Mas havia outras razões para a desaprovação. A cerimônia revertia temporariamente a hierarquia oficial, e muitos capitães eram tratados com desprezo e escárnio. Assim, os ritos não expressavam apenas uma consciência compartilhada entre os marinheiros, mas também dramatizavam as divisões da ordem social do navio. ${ }^{14}$

\footnotetext{
no Brasil Colonial, São Paulo, Companhia das Letras, 1986, p. 75.

${ }^{12}$ G. Walsh, Notícias do Brasil, São Paulo, Edusp; Belo Horizonte, Itatiaia, 1982, vol. 1.

${ }_{13}$ Edward P. Thompson, Costumbres em Comum, Barcelona, Editorial Crítica, 1995; Natalie Davis, Culturas do Povo. Sociedade e Cultura no início da França Moderna, Rio de Janeiro, Paz e Terra, 1990.

${ }^{14}$ Ressalte-se, contudo, que se por um lado o ritual de passagem da linha do Equador expressava consciência compartilhada entre os marinheiros, por outro, há pelo menos um registro recolhido por Jaime Rodrigues, narrado por um viajante estrangeiro pela América do Sul, segundo o qual os marinheiros trataram os africanos a bordo com discriminação, aproveitandose para cometer contra eles certas brincadeiras cruéis. Acredito, no entanto, que o aspecto rebelde e libertador do ritual era prevalente. Cf. Jaime Rodrigues, De Costa a costa. Escravos, marinheiros e intermediários do tráfico negreiro de Angola ao Rio de Janeiro (1780-1860), São Paulo, Companhia das Letras, 2005, p. 188.
} 


\section{Hierarquia cindida}

A cultura do marinheiro não estava, de forma nenhuma, como vimos, dissociada das difíceis condições de vida e trabalho a que era submetido no cotidiano do navio. Constituindo-se através das relações materiais com a natureza e entre os homens, ela emergia de complexas e contestadas realidades de trabalho e autoridade. Portanto, os marinheiros recorriam inconscientemente a seu rico arsenal cultural, composto por antigas tradições orais provindas de várias partes do mundo, como as descritas acima, para responderem às condições que lhes eram impostas.

Sob este aspecto, as narrativas do comerciante inglês e proprietário de navio mercante John Luccock revelam-se importantes para o entendimento dos conflitos que ocorriam frequentemente nas relações de trabalho. Luccock discorre longamente a respeito de uma viagem que fez em seu navio, do Rio de Janeiro para a região do Prata, em 1808. Dedica grande parte de seu tempo a falar sobre o comportamento dos marinheiros contratados no Brasil, insistindo no péssimo caráter daqueles homens, na sua malícia, desonestidade e insubordinação, o que lhe causou prejuízos e dissabores. ${ }^{15}$

Luccock descreve um motim desencadeado pelos marinheiros, que sob determinados aspectos configurou-se como um movimento planejado. Os trabalhadores do navio escolheram um momento apropriado para se recusarem a desempenhar normalmente suas tarefas. Esperaram que uma situação de mau tempo, prenunciando tempestade, desencadeasse o pânico no navio e tornasse o seu trabalho mais imprescindível do que nunca, para anunciar o seu protesto. A desobediência dos marinheiros às ordens de subida ao Convés para as providências de enfrentamento da tempestade colocou o Capitão do navio e um inglês, que desempenhava as funções de Imediato, em luta com os marinheiros. A tripulação inglesa muniu-se rapidamente com armas de fogo, que não chegaram a ser usadas, porque alguns marinheiros foram abatidos a pauladas, dentre eles o marinheiro Silva, que liderava o motim. Com seu líder fora de combate os marinheiros retornaram ao trabalho, mas o ambiente permaneceu tenso até o final da viagem, sendo necessária a presença permanente de um inglês armado no Convés. ${ }^{16}$

${ }^{15}$ John Luccock, Notas sobre o Rio de Janeiro e partes meridionais do Brasil, São Paulo, Editora da Universidade de São Paulo; Belo Horizonte, Itatiaia, 1975, p. 97.

${ }^{16}$ John Luccock, op. cit., p. 95. O marinheiro Silva foi mencionado várias vezes por Luccock, tal a sua importância como líder e como trabalhador marítimo típico daquele período. Luc- 
Há indicações de que o descontentamento dos amotinados se devia entre outros fatores à alimentação servida no navio. Os empresários do navio tinham mudado a maneira usual de abastecer os marinheiros. Ao invés de remunerarem em certa quantia que fosse gasta em refeições, ao longo da viagem, para que os trabalhadores pudessem se prover, os empresários optaram por instalar provisões no próprio navio, servindo-lhes a comida como parte do salário. Os trabalhadores não ficaram contentes com a comida, tampouco a forma de remuneração de sua força de trabalho, apesar de Luccock ter afirmado que os trabalhadores eram fartamente alimentados. Justificando a forma violenta com que agiu em relação ao motim dos marinheiros, o mercador acusou-os de saquearem os depósitos de mantimentos e de devorarem as provisões de queijo e arroz do navio, a ponto de ficarem doentes e quase morrerem.

Foi intrigante, contudo, a atitude dos marinheiros quando o navio aportou em Buenos Aires. A forma que encontraram para se vingarem de seus patrões foi a de apresentar denúncias de que os mesmos haviam desembarcado gêneros clandestinamente em Maldonado, e que traziam armas escondidas a bordo, ameaçando-os de morte por repetidas vezes. Essa denúncia valeu ao empresário do navio uma ordem de prisão, que custou a sua retenção a bordo durante seis semanas. Somente os marinheiros podiam deixar o navio e circular livremente pelas imediações dos portos. ${ }^{17}$

Mawe, também viajante inglês que chegou ao Brasil em 1807 e regressou a Londres em 1811, teve dificuldades bastante parecidas com as de Luccock. Antes de chegar ao Brasil, o autor viajou para a região do Rio da Prata com uma tripulação constituída por marinheiros espanhóis e portugueses. Nesta viagem registraram-se, no plano das relações de trabalho, inúmeras tensões atribuídas à intensificação do ritmo da execução das tarefas, principalmente em momentos de se enfrentar tempestades. Mawe teve também problemas

cock informa que ao regressar, antes mesmo de ser punido no Brasil embarcou para a China em outro navio mercante, dizendo também dele nunca mais ter ouvido falar. Sua biografia merece ser mais bem explorada, com o objetivo de esclarecer vários aspectos do mercado de trabalho marítimo, dentre os quais as suas características de internacionalidade, bem como as características, os contextos e os sentidos da movimentação daqueles trabalhadores pelo mundo atlântico. Exemplares, neste sentido, são os trabalhos de Rediker e Linebaugh em relação às biografias dos marinheiros John Young e Edward Coxere no século XVIII, e o recente artigo de Reis, Gomes e Carvalho sobre o africano Rufino José Maria. Cf. Marcus Rediker, op. cit., p. 79-80; Peter Linebaugh e Marcus Rediker, op. cit., p. 151, 257 e 315; João José Reis et alii, "África e Brasil entre margens: aventuras e desventuras do africano Rufino José Maria no século XIX”, Estudos Afro-Asiáticos, Vol. 26, n. 2, Rio de Janeiro, 2004, p. 257-302.

${ }^{17}$ John Luccock, op. cit., p. 97. 
nas suas relações com as autoridades, tendo seu navio, carga e ele próprio sido aprisionado em Montevidéu, no ano de $1804 .{ }^{18}$

Ainda naquela região Mawe foi detido uma segunda vez, em virtude de denúncias feitas por seu Capitão, com quem se incompatibilizara seriamente nas relações de trabalho. Mawe duvidou da integridade do comportamento de seu Capitão, e chegando ao porto de desembarque confirmou-se o que vinha ocorrendo durante a viagem: o fenômeno do isolamento do representante máximo da direção despótica do capital, situado na ponta da pirâmide social do navio. O Capitão aliou-se aos marinheiros e juntos denunciaram o proprietário do navio, revelando sua identidade inglesa, embora estivesse aportando sob bandeira espanhola naquele local. Isto foi suficiente para que o Governador expedisse ordem de prisão a Mawe. Tratava-se de um momento delicado em que no plano internacional a situação era bastante tensa. A Inglaterra estava em guerra com a França e, por esta razão, havia uma expectativa de ruptura com a Espanha, o que justificava a preocupação de Mawe em estar navegando sob bandeira espanhola em região de influência e domínio daquela nação. Naquele mesmo momento em que Mawe se fazia presente na região, ocorrera $o$ aprisionamento de fragatas nacionais espanholas pela frota inglesa do cabo Finisterra, fato que tornava sua situação ainda mais difícil.

Tanto na experiência de Luccock com marinheiros brasileiros, quanto na experiência de Mawe com marinheiros espanhóis e portugueses, pode-se verificar que havia por parte desses trabalhadores um grande domínio de informações envolvendo a situação política ligada à disputa das grandes nações pela hegemonia européia e a crise do sistema colonial. ${ }^{19}$

${ }_{18}^{18}$ J. Mawe, Viagens ao interior do Brasil, São Paulo, Edusp; Belo Horizonte, Itatiaia, 1978, p. 23-24.

${ }^{19}$ De fato, desde 1803, quando a Inglaterra se aliara à Rússia e à Áustria para lutar contra a França, desencadeou-se uma sucessão de conflitos entre essas duas aliadas que passou pelo Bloqueio Continental, em 1806, envolvendo sobretudo Portugal e Espanha, bem como suas respectivas colônias, entre elas o Brasil e a região do Rio da Prata. Esses conflitos entre nações marcando a corrida entre elas pela liderança política e econômica do mundo moderno só terminaram com a derrota de Napoleão em Waterloo e a restauração, pela segunda vez, de Luiz XVIII. O Congresso de Viena (1814-1815) restabelece o equilíbrio entre as grandes potências e a Inglaterra assume a supremacia marítima e colonial. Esta situação determinou a invasão inglesa à região colonial do Rio da Prata (Buenos Aires) por duas vezes, em 1806 e em 1808. Tal região colonial pertencia ao domínio da Espanha, tradicional inimiga da Inglaterra e Portugal, e aliada da França. Ora, toda esta conjuntura determinava uma situação muito difícil para os mercadores de nacionalidade inglesa que adentravam a região do Rio da Prata. Cf. Túlio Halperin Donghi, História da América Latina, trad. Carlos Nelson Coutinho, Rio de Janeiro, Paz e Terra, 1975; Jacques Godechot, Europa e América no Tempo de Napoleão: 1800-1815, trad. Miriam Lifchitz Moreira Leite, São Paulo, Pioneira: Editora da Universida- 
O envolvimento e a atitude dos marinheiros brasileiros, espanhóis e portugueses em relação aos comerciantes ingleses, seus patrões, revelam que estes trabalhadores tinham uma consciência singular da exploração que lhes era imposta no interior do processo de trabalho e, ao mesmo tempo, desenvolviam, em casos como estes, mecanismos ardilosos e potentes para lutar contra o seu opressor. O amplo circuito de informações que dominavam decorria da natureza mesma do próprio processo de trabalho a que estavam submetidos. O navio, antecipador da fábrica do futuro, configurava-se como um ambiente de atuação internacional, determinava uma grande rotatividade de mão de obra, exprimia um campo significativo de interação humana e constituía-se em meio de comunicação entre os continentes, e também o lugar onde primeiramente os trabalhadores de todo o mundo se comunicavam. ${ }^{20}$ Não raro, as notícias de levantes de trabalhadores em outras colônias eram trazidas ao Brasil pelos marinheiros e espalhadas aos escravos daqui. ${ }^{21}$ Por todos esses fatores, os marinheiros tinham condições de dominar as informações fundamentais da política internacional e saber, portanto, o que significava a presença de um cidadão inglês na região do Rio da Prata, num momento caracterizado por tensões e guerras como se vivia desde inícios do século XIX. Assim, tanto os marinheiros brasileiros a serviço de Luccock, quanto os espanhóis e portugueses, a serviço de Mawe, usaram a mesma estratégia para punir seus opressores. Sabendo das relações de antagonismo da Espanha para com a Inglaterra, os marinheiros provocaram a prisão e sequestro dos navios e mercadorias de seus patrões, simplesmente revelando a nacionalidade dos mesmos às autoridades de Buenos Aires e Montevidéu, bem como os acusando de estarem armados e de serem contrabandistas. A ideologia nacionalista, extremamente forte num momento que os Estados Nacionais estavam em pleno processo de constituição, e em guerra uns com os outros na disputa pela hegemonia européia, não afetava o comportamento dos marinheiros. Ao invés de se digladiarem em nome do interesse de suas respectivas nações, marinheiros espanhóis e portugueses se uniram contra o proprietário do navio, com quem conflitavam naquele momento.

de de São Paulo, 1984 (Biblioteca Pioneira de Ciências Sociais, Série "Nova Clio"); Georges Lefebvre, Napoléon, Paris, P.U.F., 1953 (Peuples et Civilizations).

${ }^{20}$ Peter Linebaugh, “Todas as Montanhas Atlânticas Estremeceram”, Revista Brasileira de História (São Paulo), vol. 6, p. 31-33.

${ }^{21}$ Luiz B. Mott, op. cit. 


\section{Controle e disciplina}

Diante de tantos e tão graves conflitos caberia, pois, o desenvolvimento de mecanismos compatíveis com os objetivos de criação do marinheiro disciplinado. O Estado brasileiro desde os primórdios de sua formação cumpriu funções importantes no sentido da neutralização da força da cultura popular, proveniente da base da pirâmide social do navio, dentre elas a de modernizar progressivamente a estrutura dos principais portos marítimos do país.

Afinal, a ascensão do Atlântico Sul e do Brasil, como componentes dinâmicos do sistema atlântico e da ordem mundial capitalista, definia como questão central a renovação da estrutura técnica de seus portos, com vistas à integração mais efetiva do movimento local de mercadorias às rotas marítimas internacionais, e, ao fazê-lo, acabava por investir, ao mesmo tempo na formação do trabalho do marinheiro e na sua transformação em mercadoria.

A cidade do Recife é uma das que testemunhou preocupações de seus governantes e homens de negócios com a modernização de seu porto. Alguns deles expunham a necessidade de que nos principais portos de sua província ${ }^{22}$ houvesse uma boa alfândega para se evitarem os furtos e descaminhos de mercadorias, e se intensificarem a vigilância e repressão à força de trabalho dos portos e dos navios. Havia uma grande preocupação com os marinheiros que fugiam de qualquer controle lançando-se ao mar, nadando para os navios que ancoravam perto da terra, passando de um para outro, escondendo-se e encontrando-se com outros marinheiros. Para "conter em subordinação e obediência os marinheiros" e controlar navios nacionais e estrangeiros, o governador daquela província contou com o trabalho de vigilância e repressão de uma fragata de guerra e com a instalação de telégrafos e sentinelas por toda a costa. ${ }^{23}$

\footnotetext{
${ }^{22}$ Dentre os membros da elite política e econômica da época preocupados com o comércio portuário destaca-se Azeredo Coutinho, que ganhou projeção por defender ideias avançadas para seu tempo, em termos de capitalismo. No primeiro volume da coleção "Roteiro do Brasil", encontram-se publicadas quatro memórias suas, sobre assuntos econômicos brasileiros. Cf. J. J. da Cunha de Azeredo Coutinho, Obras econômicas de J.J.da Cunha de Azeredo Coutinho, apres. Sérgio Buarque de Holanda, São Paulo, Cia. Editora Nacional, 1966 (Coleção "Roteiro do Brasil", vol. 1); Sobre Azeredo Coutinho, cf. E. Bradford Burns, "The Role of Azeredo Coutinho in the Enlightenment of Brasil", The Hispanic American Historical Review, XLIV, Vol. 2, Durham, MC - EUA, 1964, p. 145-160.

${ }^{23}$ F. A. Pereira da Costa, "Anais Pernambucanos, 1818-1823". Recife, Secretaria do Interior e Justiça, Arquivo Público Estadual, Vol. VIII, 1962, p. 368-369.
} 
Tais providências vão se generalizando e se aperfeiçoando, como se pode perceber pelo Decreto número 358, de meados do século XIX, que manda estabelecer "uma capitania do porto em cada província marítima do Império, onde fosse necessário, com o objetivo de fazer o policiamento naval do porto e seus ancoradouros, promover seu melhoramento, conservação, inspeção, administração dos faróis, além de matricular toda a tripulação empregada na navegação e tráfico dos portos e das costas". ${ }^{24}$ Este último objetivo alargava sem dúvida o poder de repressão e controle das classes dominantes sobre o conjunto dos trabalhadores vinculados aos portos e navios. Ainda por volta de meados do século, a epidemia da febre amarela dá ensejo ao reforço a uma tendência, que já vinha se delineando, de criação de conselhos, comissões e inspeções encarregadas de exercer um controle efetivo sobre as questões de saúde pública. Assim, em 1845, uma lei provincial cria um Conselho Geral de Salubridade na cidade do Recife, tendo o conselho por finalidade inspecionar, vigiar e prover sobre todos os assuntos que se referissem à higiene e à polícia médica. Mais ou menos à mesma época intensificam-se as inspeções de saúde nos portos, em virtude da epidemia da febre amarela. ${ }^{25}$ A atuação ampliada da polícia sanitária transcende quase sempre os objetivos ligados estritamente à saúde, ${ }^{26}$ o que permite supor nesse momento a sua utilização como instrumento decisivo de controle sobre a conduta dos trabalhadores de portos e navios.

Ao que tudo indica, havia funcionários nos portos brasileiros, sobretudo naqueles mais importantes como o do Rio de Janeiro, que auxiliavam proprietários e Capitães de navios na contratação de marinheiros para as viagens internacionais. A viagem do mercador inglês Luccock, já anteriormente referida, é ilustrativa desta questão. Os marinheiros já haviam sido contratados e o navio estava de partida. Antes, porém, um funcionário do porto adentrou a coberta e convocou todos os marinheiros para reconhecimento, após o que expressou aos comandantes ingleses seu profundo pesar e preocupação. Tratava-se, segundo o funcionário, de marinheiros que eram verdadeiros vilões, refinados e conhecidos. Não foi possível se fazer a dispensa e a recontratação, pois não havia disponibilidade de marinheiros, principalmente naquele momento em

\footnotetext{
${ }^{24}$ F. A. Pereira da Costa, op. cit., Vol. X, 1966, p. 340.

${ }^{25}$ Idem, ibidem, p. 281 e 339.

${ }^{26}$ Exemplo bastante elucidativo de como ocorre o exacerbamento de objetivos do sanitarismo o da Revolta da Vacina, insurreição ocorrida no Rio de Janeiro em 1904. Cf. Nicolau Sevcenko, A Revolta Vacina: mentes insanas em corpos rebeldes, São Paulo, Brasiliense, 1984.
} 
que os portos brasileiros haviam sido abertos para o comércio internacional e o movimento de mercadorias era intenso. De qualquer forma, o funcionário recomendou que a vigilância fosse intensificada, e em caso de necessidade dessem imediatamente parte ao Chefe de Polícia, em qualquer porto que ancorassem, para que os marinheiros fossem severamente castigados por seu comportamento. ${ }^{27}$

O problema de escassez de marinheiros e de disciplina de trabalho atingia generalizadamente a Marinha mercante e a militar. Aliás, por volta de 1700 o trabalho marítimo havia sido inteiramente standartizado. Marinheiros circulavam de navios para navios, mesmo de navios mercantes para navios reais, para navios de pirataria ou guerra, necessitando para todos eles executar basicamente as mesmas tarefas, que requeriam as mesmas habilidades. ${ }^{28} \mathrm{~A}$ Marinha militar brasileira, tendo desde o início a percepção da intensidade do problema referente à formação e disciplinarização da mão de obra marítima, reconheceu o papel que tinha a desempenhar nesta questão.

Considerou, por exemplo, que uma vez recrutados e colocados a serviço da Marinha, algumas providências teriam que ser tomadas para a disciplinarização daqueles homens. Dentre essas providências, considerou que o aquartelamento adequado dos recrutados era de suma importância para o desenvolvimento e a manutenção da disciplina entre os marinheiros. Além disso, novas leis teriam que ser criadas, para que eles mantivessem a mais estrita e rigorosa disciplina no navio e conservassem a tensa cadeia de subordinação que deveria se estabelecer desde o mais graduado oficial até o simples grumete. Discutiu-se então (sobretudo a partir do grande levante de marinheiros ocorrido na Ilha das Cobras no Rio de Janeiro em 1831) a elaboração de um novo Regimento, a regulamentação dos Corpos da Armada e da Artilharia e dos Serviços de bordo dos navios da Marinha. Seria necessário também cuidar das promoções dos Oficiais e suas reformas e organizar uma legislação penal que mantivesse os soldados na mais estrita disciplina. Com um novo Regimento Provisional substituindo o vigente, dizia a Ministro da Marinha, seria possível vencer a impunidade e desestimular a insubordinação. A regulamentação dos Serviços de bordo dos navios manteria os marinheiros em permanente ocupação, conservando-lhes a energia e o vigor, e preservandoos dos vícios e de toda sorte de males. ${ }^{29}$

\footnotetext{
27 John Luccock, op. cit., p. 95.

${ }^{28}$ Marcus Redicker, op. cit., p. 83.

${ }^{29}$ Relatório do Ministério da Marinha do ano de 1831, apresentado pelo Ministro Joaquim
} 
Mas o investimento mais pesado da Marinha militar brasileira para tentar soldar essa fratura referiu-se à criação de instituições que pudessem, de forma diferenciada, ministrar educação formativa aos marinheiros comuns e aos que ocupavam postos superiores na pirâmide social do navio. As escolas para estes últimos formariam os oficiais detentores de postos médios e elevados no interior da instituição. Aos marinheiros, as escolas técnicas encarregar-seiam de dar uma formação técnica que os habilitasse para as tarefas mais rudes do navio e uma formação moral neutralizadora de sua cultura diversificada e rebelde.

A formação dos oficiais da Marinha mereceu, desde o início de sua constituição, uma atenção particular. Em 1827 o Ministro da Marinha chama atenção para a necessidade de montar um sistema próprio de educação para formar of iciais. ${ }^{30}$ Seu sucessor reiterava esses argumentos, e acrescentava que os oficiais da Armada são a alma e a vida da Marinha de Guerra e os que dão impulso à Força Naval. ${ }^{31}$ Alguns anos mais tarde os argumentos de ordem e disciplina aparecem mais claramente vinculados à necessidade de educar e formar convenientemente os oficiais. Esta educação teria que formá-los para a mais rigorosa disciplina e a mais estrita organização, obediência, severidade e regularidade do serviço de bordo para que soubessem passar esses valores a quem iam dirigir no futuro. ${ }^{32}$ Nesse sentido duas providências foram tomadas quase simultaneamente: a de enviar oficiais para serem treinados em Marinhas de países estrangeiros e a fundação de escolas para formação de oficiais.

Entre 1828 e 1833 foram apresentadas pelos Ministros da Marinha, sugestões de mandar certo número de jovens oficiais brasileiros para servirem como voluntários em França e na Inglaterra à custa do Estado. Caberia também a eles inteirarem-se das novidades tecnológicas e pesquisarem a estrutura e o funcionamento da Força Naval dessas nações, apresentando os resultados por escrito para a Marinha brasileira. ${ }^{33}$ Esta prática teve continuidade, tendo sido enviados vários Segundos-Tenentes para navios norte-americanos e ingleses, por volta de meados do século XIX. Os Ministros avaliavam positivamente

José Rodrigues Torres à Assembléia Geral Legislativa de 1832, p. 13-15.

${ }^{30}$ Idem, 1827, apresentado pelo Ministro Diogo Jorge de Brito à Assembléia Geral Legislativa, p. 6.

${ }^{31}$ Idem, 1828, apresentado pelo Ministro Miguel de Souza Alvim, p. 4.

${ }^{32}$ Relatório de 1842, apresentado por Jacinto Roque de Souza Pereira, Chefe de Divisão e $1^{\circ}$. Comandante da Nau Pedro II ao Ministro da Marinha, p. 13.

${ }^{33}$ Relatório de 1828, p. 4. 
os resultados desse tipo de treinamento, bem como o material trazido pelos oficiais para ser aproveitado na organização da Marinha brasileira. ${ }^{34}$

A segunda providência igualmente importante na formação de oficiais, preparados para subordinar os marinheiros à disciplina no processo de trabalho, foi também sendo implementada logo no início da formação da Marinha. Talvez a instituição mais importante para atender a esses objetivos tenha sido a Academia dos Guardas-Marinha.

A intenção de recrutar seus alunos entre os membros das classes dominantes foi desde logo evidenciada. ${ }^{35}$ Destinada a formar um viveiro de oficiais da Marinha, a Academia deveria preferir os filhos de oficiais da Armada e do Exército que maior serviço tivessem prestado ao país. Com isso estar-se-ia admitindo jovens que já teriam adquirido com seus pais o exemplo de disciplina e subordinação. Ademais, o número de vagas oferecido deveria ser limitado, para assegurar a qualidade dos ingressantes. ${ }^{36}$

Pouco tempo depois de ter sido fundada já havia um plano para sua reorganização e reforma, sob o argumento de que sua importância requeria um espaço bem maior do que os três cubículos do Mosteiro onde estava instalada. ${ }^{37}$ A comissão formada para estudar a questão propôs sua transferência

\footnotetext{
${ }^{34}$ Relatório do Ministério da Marinha de 1844, apresentado pelo Ministro Antonio Francisco de Paula e Hollanda Cavalcanti D'Albuquerque à $2^{\text {a }}$. Sessão da $6^{\text {a }}$. Legislatura da Assembléia Geral Legislativa, p. 4; idem, 1845, $3^{\text {a }}$. Sessão, 6a. Legislatura, p. 7-8.1

${ }^{35}$ Essa forma de recrutamento da Marinha brasileira tem raízes históricas e vem da tradição da estrutura organizacional da Marinha portuguesa. Pelo regulamento português de 1782 da Academia Real da Marinha, exigia-se, para ser Guarda-Marinha, que o candidato fosse fidalgo ou filho de oficial da Marinha ou do Exército. Tal estrutura foi transplantada legal e materialmente para o Brasil em 1807. Uma das naus que compunha a frota que trouxe a família real, a do Conde Dom Henrique, transportou toda a Academia Real dos GuardasMarinha para o Brasil. Com a Independência, 98 desses oficiais portugueses aderiram à causa brasileira, não o fazendo apenas 27. Essa formação da Marinha, chefiada à época pelo Lorde Thomas Alexander Cochrane, completa-se com a contratação de 19 altos oficiais da Inglaterra e três da França. Cf. H. Boiteux, Os nossos almirantes, Rio de Janeiro, Imprensa Naval, 1915; Eurípedes Simões de Paula, “A Marinha”. In: Sérgio Buarque de Holanda (org.), O Brasil Monárquico, Tomo II, Vol. 4, São Paulo, Difusão Européia do Livro, 1971; José Murilo Carvalho, "As Forças Armadas na Primeira República: o poder desestabilizador”. In: Fausto, B. (org.), O Brasil Republicano, Tomo III, Vol. 2, Rio de Janeiro, Difel, 1977, p. 189; A. M. Azevedo, "Lorde Cochrane, primeiro almirante brasileiro", Revista de História, São Paulo, 1954, 19: 101-130; Carlos da Fonseca, A evolução da Marinha brasileira. Sinopse, 18221958, Rio de Janeiro, 1961, p. 7, 9 e 20.

${ }^{36}$ Relatório do Ministério da Marinha apresentado pelo Ministro Joaquim José Rodrigues Torres à Sessão Ordinária da Assembléia Geral Legislativa de 1838, p. 26-27.

${ }^{37}$ Relatório do Ministério da Marinha apresentado pelo Ministro Joaquim José Rodrigues Torres à Assembléia Geral Legislativa de 1828, p. 10; Relatório e proposta apresentados pelo Conselheiro Marquês de Paranaguá à Assembléia Geral Legislativa de 1830, p. 8.
} 
para o extremo sul do Arsenal da Marinha, em espaço que poderia contemplar lugar para aulas, livrarias e outras acomodações, além de um terraço próprio para observações e exercícios de astronomia. ${ }^{38}$

A Academia funcionava bem, mas ressentia-se de ensinamentos práticos aos oficiais que ali se formavam. As sucessivas discussões a este respeito conduziram à decisão de transferi-la para um navio. A formação prática aliava-se ao argumento da disciplina. Funcionando em um navio, os futuros oficiais estariam mais distanciados das tentações de terra e ao mesmo tempo isso iria acostumá-los às regras e aos princípios da severa disciplina quando chegassem a oficiais da Marinha. ${ }^{39}$ Algum tempo depois o Ministro avaliava que na transferência da Academia dos Guardas-Marinha para a Nau Pedro II aumentaram as despesas, mas em contrapartida iria melhorar sensivelmente a formação dos oficiais. ${ }^{40}$

A permanente discussão sobre a formação dos oficiais levava sempre a novas avaliações. Após um balanço dos primeiros cinco anos de funcionamento da Academia, apontou-se a limitação de que a Academia ficava num navio fundeado, e essa forma de treinamento deveria ser trocada por outra que ocorresse numa Fragata em alto-mar. Foi assim que se passou a adotar o emprego de alguns navios em viagem de longo curso para a aprendizagem prática dos oficiais marinheiros, sobretudo a Fragata Constituição, um dos melhores navios da época, vindo da Inglaterra. ${ }^{41}$

Se as instituições encarregadas de formar membros das classes dominantes situadas no topo da pirâmide do navio tinham as características apontadas acima, a educação da base dessa mesma pirâmide perseguia caminhos e objetivos bastante diferentes. Avaliava-se que no Brasil a Marinha Mercante e os navios pesqueiros eram de porte insignificante, razão pela qual não eram capazes de formar marinheiros para a Marinha Militar. Os recrutados eram homens bisonhos, apanhados a esmo, e precisariam ser educados para serem úteis à Marinha Militar. ${ }^{42}$ Inicialmente este trabalho foi bastante assistemático,

\footnotetext{
${ }^{38}$ Relatório do Ministério da Marinha apresentado pelo Ministro Joaquim José Rodrigues Torres à Assembléia Geral Legislativa de 1833, p. 14.

${ }^{39}$ Relatório de 1838 , p. 27.

${ }^{40}$ Relatório do Ministério da Marinha apresentado pelo Ministro Joaquim José Rodrigues Torres à $2^{\text {a }}$. Sessão da $6^{\text {a }}$. Legislatura da Assembléia Geral Legislativa de 1842, p.13.

${ }^{41}$ Relatório do Ministério da Marinha apresentado pelo Ministro Francisco de Paula e Hollanda Cavalcante D'Albuquerque à $2^{\mathrm{a}}$. Sessão da $6^{\mathrm{a}}$. Legislatura da Assembléia Geral Legislativa de 1844, p. 12-14.

${ }^{42}$ Relatório do Ministério da Marinha apresentado pelo Ministro Joaquim José Rodrigues Torres à Assembléia Geral Legislativa de 1843, p. 9.
} 
resumindo-se a recolher meninos a bordo ensinando-os a ler, escrever e manejar armas. ${ }^{43}$ Mas logo essa atividade evoluiu para a criação de duas importantes instituições: as Companhias de Aprendizes Artífices e as Companhias de Aprendizes Marinheiros. As primeiras recrutavam meninos pobres para formar os futuros operários, mestres e contramestres das oficinas dos Arsenais da Marinha. As segundas, trabalhando com crianças e adolescentes de 10 a 17 anos, preocupavam-se com a formação de marinheiros para os navios. Os alunos tinham uma jornada que se iniciava às 5 horas da manhã e encerrava-se às 10 horas da noite. Ambas as escolas enfatizavam que a educação oferecida deveria subordiná-los a uma disciplina regular e uniforme e dotar os alunos das características de asseio e subordinação. Tal educação, oferecida a bordo de navios, deveria permitir aos meninos o menor tempo possível de permanência em terra para que se desviassem das distrações e se libertassem do domínio dos vícios e das paixões. ${ }^{44}$ Em meados do século, um Comandante Geral da Marinha do Rio, ao solicitar a criação de mais uma Companhia de Aprendizes Marinheiros, apresenta bons resultados ao Ministro da Marinha, quanto à transformação de meninos abandonados em bons marinheiros. ${ }^{45}$

Por volta de 1850, inicia-se outra fase da Marinha, caracterizada pelo surgimento do navio a vapor. Trata-se, então, de um momento propício para marcar o fim de uma periodização histórica, uma vez que o processo de inovação tecnológica transforma a dinâmica da organização do processo de trabalho no navio e influi na organização do processo disciplinar do marinheiro.

Contudo, não poderíamos encerrar esta discussão sem antes lembrar que, em âmbito nacional, as relações de trabalho e produção no latifúndio escravista monopolizaram as atenções das grandes interpretações sobre a identidade política, social e cultural brasileira. Não queremos negar a importância desses componentes da formação do Estado no Brasil. É evidente que a estrutura da propriedade e a escravidão negra marcaram grandemente o perfil das instituições brasileiras e a cultura política de seu povo. Esta preocupação bipolar, centrada na relação senhor-escravo, ganhou certa complexidade com as preocupações historiográficas subsequentes de resgatar o significado do homem livre e pobre na lógica do colonialismo escravista brasileiro. Isto sig-

\footnotetext{
${ }^{43}$ Relatório do Ministério da Marinha apresentado pelo Ministro José Pereira Pinto à Assembléia Geral Legislativa de 1836, p. 8.

${ }^{44}$ Relatório do Ministério da Marinha de 1838, p. 12; Idem, de 1836, p. 8; Idem, de 1842, p. 12-13; Idem, 1842, p. 9.

${ }^{45}$ Relatório do Comandante Geral Pedro Cunha, do Quartel do Corpo de Imperiais Marinheiros em Villegaignon, apresentado ao Ministro da Marinha, 1844.
} 
nificou um passo importante na superação daquele esquema interpretativo dual. Contudo, dificilmente chegaríamos a um entendimento dos componentes globais do Estado que se funda no século XIX se abdicássemos do conhecimento da atividade marítima e de seus trabalhadores. Estes, por sua importância numérica e sua significação na formação de uma cultura popular e política no Brasil. Aquela, por sua importância econômica e por ter-se constituído em instrumento dos governantes para o controle político e ideológico dos trabalhadores no interior do processo de trabalho marítimo e nas diversas rebeliões que ameaçavam a unidade nacional. 